\title{
PROPRIEDADES QUÍMICAS E CÔMPUTO QUÍMICO DOS AMINOÁCIDOS DA FARINHA E CONCENTRADO PROTÉICO DE FEIJÃO GUANDU (Cajanus cajan (L.) Millsp)
}

\author{
IVONE YURIKA MIZUBUTI * \\ LUIZ WALDEMAR DE OLIVEIRA SOUZA ** \\ OSWALDO BIONDO JÚNIOR ** \\ ELZA IOUKO IDA *
}

\begin{abstract}
Esta pesquisa teve por objetivo investigar as propriedades químicas e cômputo químico dos aminoácidos da farinha e de concentrado protéico de feijão guandu (Cajanus cajan (L.) Millsp). A farinha apresentou composição química adequada em relação a outras leguminosas. O procedimento de extração aquosa de proteína, a partir de grãos de feijão guandu com $25,73 \%$ de proteína, permitiu a obtenção de concentrado protéico com $52,47 \%$ de proteína, em base seca, compreendendo concentração da ordem de 103,85\%. O concentrado protéico de feijão guandu apresentou composição química adequada, sendo que cinzas e açúcares solúveis foram concentrados 122,17 e $21,86 \%$, respectivamente, em relação ao grão. Os níveis de aminoácidos no concentrado protéico foram similares aos de farinha de guandu, porém, a metionina foi concentrada em $42,64 \%$. O cômputo químico indicou que os aminoácidos limitantes primários na farinha e concentrado protéico foram os sulfurados totais. A composição química da farinha e do concentrado protéico de guandu indicou potencialidade para utilização de ambos como componentes de alimentos para seres humanos e animais.
\end{abstract}

\section{INTRODUÇÃO}

O feijão guandu (Cajanus cajan (L.) Millsp) é uma leguminosa da família Fabaceae de cultura perene, cultivada na Ásia, África e América do Sul (SALUNKHE et al., 1985; KRISHNA \& BHATIA, 1985), que se adapta em clima tropical e subtropical, com produtividade média de $699 \mathrm{~kg} / \mathrm{ha}$.

* Professores Doutores, Departamento de Zootecnia e Departamento de Tecnologia de Alimentos e Medicamentos, respectivamente, Universidade Estadual de Londrina, Londrina - PR. (e-mail: mizubuti54@hotmail.com).

** Alunos de Graduação de Medicina Veterinária e Farmácia e Bioquímica, respectivamente, bolsistas do programa PIBIC/CNPq/UEL, Londrina - PR. 
Na República Dominicana e em Trinidade foram encontradas variedades que produziram 2.194 e $1.667 \mathrm{~kg} / \mathrm{ha}$, respectivamente (SALUNKHE et al., 1986).

No Brasil, o Instituto Agronômico do Paraná (IAPAR) lançou no mercado, em 1990, uma variedade anã e precoce de guandu denominada IAPAR 43 aratã, cuja produção variou de 1.000 a 2.000 kg/ha, em ciclo de 140 dias, quando semeada ao final de dezembro e início de janeiro.

A grande variabilidade na composição química de diferentes leguminosas, tais como, dependência do cultivar, localização geográfica e condições de crescimento foram descritas por SALUNKHE et al. (1985). Em geral, os grãos de leguminosas apresentam teores de 20 a 30\% de proteína; 1 a 7\% de lipídios e 2 a $3 \%$ de minerais.

SINGH \& JAMBUNATHAN (1981) observaram que o grão integral de feijão guandu apresenta de 21,1 a $28,1 \%$ de proteína bruta, enquanto que GOMEZ BRENES et al., (1976) obtiveram teores entre 18,3 e 24,4\%.

A composição química de feijão guandu contém de 1,07 a 2,8\% de extrato etéreo (SALUNKHE et al., 1986, SOUZA et al., 1991); 5,43 a 10,20\% de fibra bruta (SOUZA et al., 1991; SALUNKHE et al., 1986; FIALHO \& ALBINO, 1983); 53,80 a 62,90\% de extrato não nitrogenado (FIALHO \& ALBINO, 1983; SALUNKHE et al., 1986); 3,84 a 5,72\% de matéria mineral (FIALHO \& ALBINO, 1983; SOUZA et al., 1991); 2,32 a 6,1\% de açúcares solúveis (SINGH et al., 1984a; SINGH et al., 1989) e 39,00 a 58,90\% de amido (SALUNKHE et al., 1986).

O conteúdo mineral de feijão guandu varia conforme a procedência (SANKARA RAO \& DEOSTHALE, 1981; FIALHO \& ALBINO, 1983; SINGH et al., 1984b; SALUNKHE et al., 1985; VILELA \& EL-DASH, 1985; SALUNKHE et al., 1986; SOUZA et al., 1991).

As leguminosas foram descritas como boas fontes de proteínas disponíveis, quando comparadas com produtos de origem animal, havendo porém a necessidade de avaliação química e biológica para recomendar o seu uso (JANSEN, 1978). BODWELL (1980) salientou a importância da qualidade da proteína e não apenas de sua quantidade. Proteína de alta qualidade foi definida por HOPKINS \& STEINKE (1978) por apresentar boa composição em aminoácidos. EUSÉBIO et al., (1968) e JANSEN (1978) também afirmaram que a qualidade da proteína dependia do padrão de aminoácidos presentes na proteína alimentar e da sua disponibilidade.

A qualidade da proteína dos alimentos pode ser avaliada mediante métodos químicos, biológicos, microbiológicos e ensaios "in vitro". Nos métodos químicos determinam-se os escores dos aminoácidos ou cômputo 
químico, que fornece os aminoácidos limitantes (WALKER, 1983 e JANSEN, 1978).

Tendo em vista a importância de leguminosas na alimentação humana e animal, este trabalho se propôs a investigar as propriedades químicas e cômputo químico dos aminoácidos de farinha e concentrado protéico de feijão guandu (Cajanus cajan (L.) Millsp).

\section{MATERIAL E MÉTODOS}

Foram utilizados grãos de feijão guandu (Cajanus cajan (L) Millsp), variedade IAPAR 43 - aratã, cedidos pelo Instituto Agronômico do Paraná (Londrina, Pr).

A farinha foi obtida pela moagem de grãos inteiros, classificados com peneira de malha 60 . O concentrado protéico foi obtido pela extração aquosa de proteína solúvel em $\mathrm{pH} 8,5$, utilizando a relação líquido : sólido de 5:1 (v/p). O extrato protéico foi seco por atomização, empregando-se as seguintes condições: temperatura de entrada da câmara de $160{ }^{\circ} \mathrm{C}$; temperatura de saída da câmara de $90 \stackrel{\circ}{\circ} \mathrm{C}$; bico rotativo de $25.000 \mathrm{rpm}$ e pressão do produto para entrada no secador de 0,25 bar. A secagem foi conduzida com uso apenas de ar do exaustor e sem injeção de gás.

Os teores de umidade, proteína, fibra bruta, extrato etéreo, cinzas e fósforo foram determinados segundo metodologias descritas pela AOAC (1990). Os teores de açúcares (glicídios não redutores em sacarose) e amido, foram determinados, respectivamente, conforme procedimentos adotados pelo Laboratório Nacional de Referência Animal - LANARA (BRASIL, 1981) e pela Fundação de Assistência ao Estudante (FAE) (1988).

Os teores de alguns macro ( $\mathrm{Ca}, \mathrm{P}, \mathrm{Mg}, \mathrm{K}$ e S) e microminerais ( $\mathrm{Cu}, \mathrm{Fe}, \mathrm{Zn}$, Mn e B) foram determinados em espectrofotômetro de absorção atômica (marca PERKIN - ELMER, modelo 2386), conforme recomendações de SULLIVAN \& CARPENTER (1993).

A composição em aminoácidos de farinha e concentrado protéico de feijão guandu foi quantificada conforme procedimento descrito por SPACKMAN et al. (1958) e MOORE \& STEIN (1963) e o cômputo químico determinado conforme recomendações de LAJOLO et al. (1982).

\section{RESULTADOS E DISCUSSÃO}

As propriedades químicas de farinha e concentrado protéico de feijão guandu foram avaliadas inicialmente pela composição química, cujos valores médios, em base seca, estão apresentados na Tabela 1. 


\section{TABELA 1 - COMPOSIÇÃO QUÍMICA DE FARINHA E CONCENTRADO PROTÉICO DE FEIJÃO GUANDU}

\begin{tabular}{lcc}
\hline Teor $(\%)$ & Farinha* & $\begin{array}{c}\text { Concentrado } \\
\text { Protéico* }\end{array}$ \\
\hline Extrato etéreo & 1,83 & 0,08 \\
Fibra Bruta & 10,20 & 0,17 \\
Proteína Bruta & 25,73 & 52,45 \\
Cinzas & 4,69 & 10,42 \\
Açúcares solúveis & 12,67 & 15,44 \\
Amido & 46,77 & 19,55 \\
\hline
\end{tabular}

${ }^{*}$ Em base seca, umidade da farinha $=12,15 \%$ e do concentrado $=5,28 \%$.

A farinha de guandu apresentou teor de proteína bruta superior ao descrito na literatura, com variação de 15,5 a $24,2 \%$ de proteína (FAO, 1970; SINGH et al., 1981; FIALHO \& ALBINO, 1983; SINGH et al., 1984a; SALUNKHE et al., 1985; VILELA \& EL-DASH, 1985; SINGH et al., 1989; SOUZA et al., 1991). Entretanto, SALUNKHE et al. (1985) e SALUNKHE et al. (1986) descreveram teores de até 28,5 e $26,8 \%$ de proteína, respectivamente.

Em comparação com outras leguminosas, o teor de proteína $(25,73 \%)$ foi inferior ao da soja integral (Glycine max (L.) Merri) com 44,03\%, farelo de amendoim (Arachis hypogaea L.) com $51,78 \%$, feijão branco cozido (Phaseolus vulgaris) com $28,47 \%$ e feijão caupi (Vigna unguiculata) integral, com valores médios de 26,67\% (EMBRAPA-CNPSA, 1991).

Os teores de extrato etéreo $(1,83 \%)$ e cinzas $(4,69 \%)$ foram similares aos descritos na literatura, com valores que variam de 1,17 a 1,83\% e de 4,29 a 4,97\%, respectivamente (FIALHO \& ALBINO, 1983; VILELA \& EL-DASH, 1985; SALUNKHE et al., 1986 e SINGH et al., 1989). Porém, teores menores que $3,08 \%$ de extrato etéreo e $6,29 \%$ de cinzas foram citados por SOUZA et al., (1991).

Os teores de fibra bruta $(10,20 \%)$ foram superiores aos descritos por SINGH et al. (1984a) e SOUZA et al. (1991), ou seja, 6,57 e 5,97\%, respectivamente. Todavia, teores similares de 8,99 a $11,49 \%$ foram observados por vários investigadores (FIALHO \& ALBINO, 1983; VILELA \& EL-DASH, 1985; SALUNKHE et al., 1986; SINGH et al., 1989).

Os teores de açúcares solúveis de farinha de feijão guandu (12,67\%) foram superiores ao teor médio de 4,31\%, observados por SINGH et al. (1984a); SALUNKHE et al. (1986) e SINGH et al. (1989). O teor de amido (46,77\%) foi menor que os encontrados por SINGH et al. (1984a); SALUNKHE et al. (1986); SINGH et al. (1989) e SOUZA et al. (1991), com média de 48,9\%. 
O conteúdo mineral da farinha e do concentrado protéico de feijão guandu, em base seca, pode ser observado na Tabela 2. O teor de cálcio $(0,15 \%)$ encontrado na farinha foi semelhante aos descritos por SANKARA RAO \& DEOSTHALE (1981); FIALHO \& ALBINO (1983); SINGH et al. (1984b); SALUNKHE et al. (1985); VILELA \& EL-DASH (1985); SALUNKHE et al. (1986) e SOUZA et al. (1991). Os teores de fósforo $(0,45 \%)$ e de magnésio $(0,17 \%)$ também mostraram-se similares aos observados por SANKARA RAO \& DEOSTHALE (1981); SINGH et al. (1984b); SALUNKHE et al. (1985); VILELA \& EL-DASH (1985); SALUNKHE et al., (1986) e SOUZA et al. (1991), que encontraram teores médios de 0,366 e $0,158 \%$, respectivamente. Já o teor de potássio $(1,70 \%)$ da farinha mostrou-se superior aos apresentados por SINGH et al. (1984b); SALUNKHE et al. (1986) e SOUZA et al. (1991), ao redor de 1,34\%. O teor de enxofre $(0,17 \%)$ foi semelhante aos descritos por SALUNKHE et al. (1986) e SOUZA et al. (1991).

Os teores de $\mathrm{Cu}(13,09 \mathrm{ppm})$ e $\mathrm{Fe}(43,82 \mathrm{ppm})$ foram inferiores aos citados por SOUZA et al. (1991), 23 e 83,52 ppm, respectivamente, enquanto que os teores de $\mathrm{Zn}(33,0 \mathrm{ppm})$ e $\mathrm{Mn}(23,33 \mathrm{ppm})$ revelaram-se similares.

Todos os elementos minerais analisados no concentrado protéico de feijão guandu (Tabela 2), com exceção de boro, apresentaram conteúdos maiores do que a farinha.

\section{TABELA 2 - CONTEÚDO MINERAL DE FARINHA E CONCENTRADO PROTÉICO DE FEIJÃO GUANDU}

\begin{tabular}{lcc}
\hline Minerais & Farinha* & Concentrado protéico* \\
\hline Cálcio (\%) & 0,15 & 0,26 \\
Fósforo total (\%) & 0,45 & 0,98 \\
Magnésio (\%) & 0,17 & 0,35 \\
Potássio (\%) & 1,70 & 3,31 \\
Enxofre (\%) & 0,17 & 0,39 \\
Cobre (ppm) & 13,09 & 26,39 \\
Ferro (ppm) & 43,82 & 74,43 \\
Zinco (ppm) & 33,00 & 69,15 \\
Manganês (ppm) & 23,33 & 46,45 \\
Boro (ppm) & 14,00 & 11,08 \\
* Em base seca, umidade da farinha $=12,15 \%$ e do concentrado $=5,28 \%$.
\end{tabular}

A Tabela 3 apresenta a composição em aminoácidos da farinha e concentrado protéico de feijão guandu. Foram observadas altas concentrações de lisina e de proteína $(7,17$ e 7,04 g/100 g, respectivamente) e baixas concentrações de metionina e de proteína. Estas informações confirmam que as proteínas de leguminosas são deficientes em aminoácidos sulfurados e ricas em lisina (SATHE et al., 1984). 
TABELA 3 - TEORES DE AMINOÁCIDOS DA FARINHA E CONCENTRADO PROTÉICO DE FEIJÃO GUANDU

\begin{tabular}{lrc}
\hline Aminoácidos (g/100 g proteína) & Farinha* & Concentrado protéico* \\
\hline Ácido aspártico & 13,12 & 12,42 \\
Treonina & 4,41 & 4,11 \\
Serina & 5,21 & 5,28 \\
Ácido glutâmico & 25,16 & 25,76 \\
Prolina & 5,11 & 4,28 \\
Glicina & 4,32 & 4,18 \\
Alanina & 5,31 & 5,70 \\
Valina & 4,62 & 6,07 \\
Metionina & 1,29 & 1,84 \\
Isoleucina & 5,29 & 5,54 \\
Leucina & 9,07 & 8,97 \\
Tirosina & 2,28 & 1,75 \\
Fenilalanina & 11,13 & 13,19 \\
Histidina & 4,21 & 4,46 \\
Lisina & 7,17 & 7,04 \\
Arginina & 10,90 & 10,37 \\
Triptofano & - & - \\
Cistina & - & - \\
\hline
\end{tabular}

* Em base seca, umidade da farinha $=12,15 \%$ e do concentrado $=5,28 \%$.

O aminograma (Tabela 3) para farinha de feijão guandu apresentou teores superiores de ácido aspártico, treonina, ácido glutâmico, alanina, fenilalanina e arginina, enquanto que os teores de outros aminoácidos foram similares aos descritos por EUSÉBIO et al. (1968); ELIAS et al. (1976); EUSÉBIO et al. (1977); SINGH et al. (1981); SINGH et al. (1984a); SALUNKHE et al. (1986); SOUZA et al. (1991) e SINGH et al. (1993).

A metodologia utilizada para determinação de aminoácidos, nas duas amostras não quantificou os aminoácidos triptofano e cistina. MAURON (1973) descreveu que, a hidrólise ácida das proteínas para análise de aminoácidos provoca a destruição completa do triptofano e parcial da cistina.

A descrição do teor de aminoácidos no concentrado protéico de feijão guandu (Cajanus cajan (L.) Millsp) não foi encontrada na literatura. Entretanto, dos aminoácidos analisados nesta amostra, apenas tirosina e treonina apresentaram teores abaixo do concentrado protéico de soja descrito por PEARSON (1983). Comparado com o concentrado protéico de feijões (Phaseolus vulgaris) apenas a tirosina mostrou níveis inferiores, enquanto que, os aminoácidos serina, metionina, isoleucina e leucina apresentaram níveis similares. Os outros aminoácidos analisados apresentaram teores superiores em comparação com concentrados protéicos de feijões descritos por CHANG \& SATTERLEE (1979). 
Embora a composição de aminoácidos da proteína seja importante, esta é apenas indicativa da qualidade nutricional, e não determina por si só, a qualidade do alimento. $O$ perfil de aminoácidos de diferentes proteínas pode ser comparado de forma relativamente simples pelo método de cômputo químico, utilizando a proteína provisional da Food and Agriculture Organization of the United Nations (FAO) ou de ovo como referência padrão. Nas Tabelas 4 e 5 são mostrados os cômputos químicos da farinha e concentrado protéico de feijão guandu (cajan Cajanus (L.) Millsp), respectivamente, em relação à proteína da $\mathrm{FAO}$ e à proteína de ovo, segundo LAJOLO et al. (1982).

\section{TABELA 4 - TEORES DE AMINOÁCIDOS ESSENCIAIS E CÔMPUTO QUÍMICO DOS AMINOÁCIDOS DE PROTEÍNA DA FARINHA DE FEIJÃO GUANDU EM RELAÇÃO À PROTEÍNA PADRÃO DA FAO E DE OVO}

\begin{tabular}{|c|c|c|c|c|c|}
\hline Aminoácidos & $\begin{array}{l}\text { Proteína da } \\
\text { farinha } \\
\text { (mg/g prot.) }\end{array}$ & $\begin{array}{c}\text { Proteína } \\
\text { da FAO } \\
\text { (mg/g prot.) }\end{array}$ & $\begin{array}{l}\text { Cômputo } \\
\text { químico }\end{array}$ & $\begin{array}{c}\text { Proteína } \\
\text { de ovo }{ }^{1} \\
\text { (mg/g prot.) }\end{array}$ & $\begin{array}{l}\text { Cômputo } \\
\text { químico }\end{array}$ \\
\hline Isoleucina & 52,90 & 40,00 & 1,3225 & 54,00 & 0,9796 \\
\hline leucina & 90,70 & 70,00 & 1,2957 & 86,00 & 1,0546 \\
\hline Lisina & 71,70 & 55,00 & 1,3036 & 70,00 & 1,0243 \\
\hline Metionina & 12,90 & . & - & - & - \\
\hline Cistina & - & - & - & - & - \\
\hline $\begin{array}{l}\text { Sulfurados } \\
\text { totais }\end{array}$ & 12,90 & 35,00 & 0,3686 & 57,00 & 0,2263 \\
\hline Fenil alanina & 111,30 & - & - & - & - \\
\hline Tirosina & 22,80 & - & - & - & - \\
\hline $\begin{array}{l}\text { Aromáticos } \\
\text { totais }\end{array}$ & 134,10 & 60,00 & 2,2350 & 93,00 & 1,4419 \\
\hline Treonina & 44,10 & 40,00 & 1,1025 & 47,00 & 0,9383 \\
\hline Triptofano & - & 10,00 & - & 17,00 & - \\
\hline Valina & 46,20 & 50,00 & 0,9240 & 66,00 & 0,7000 \\
\hline
\end{tabular}

De acordo com a Tabela 4 verifica-se que, o cômputo químico dos aminoácidos da farinha de feijão guandu em relação à proteína da FAO apresentou limitação primária, ao redor de 63,14\% de aminoácidos sulfurados e secundária, ao redor de $7,60 \%$ de valina. Com relação à proteína de ovo observa-se que houve limitação primária de aminoácidos sulfurados, secundária de valina e terciária de treonina, com déficit destes aminoácidos da ordem de 77,37\%, 30,00\% e 6,17\%, respectivamente.

SOUZA et al. (1991) determinaram o cômputo químico de aminoácidos de feijão guandu (Cajanus cajan (L.) Millsp) em relação à proteína padrão da 
FAO e observaram que houve limitações dos aminoácidos sulfurados, valina e isoleucina, com déficit de $43 \%, 40 \%$ e $38 \%$, respectivamente.

O cômputo químico dos aminoácidos do concentrado protéico de feijão guandu (Tabela 5) em relação à proteína da FAO indicou apenas a limitação de aminoácidos sulfurados totais, com déficit de 47,43\%. Entretanto, quando se comparou o cômputo químico em relação à proteína de ovo verificou-se que os aminoácidos limitantes primários, secundários e terciários foram os sulfurados totais, treonina e valina, respectivamente (déficit de 67,72\%, 12,55\% e 8,03\%).

\section{TABELA 5 - TEORES DE AMINOÁCIDOS ESSENCIAIS E CÔMPUTO QUÍMICO DOS AMINOÁCIDOS DA PROTEÍNA DO CONCENTRADO PROTÉICO DE FEIJÃO GUANDU EM RELAÇÃO À PROTEÍNA PADRÃO DA FAO E DE OVO}

\begin{tabular}{|c|c|c|c|c|c|}
\hline Aminoácidos & $\begin{array}{l}\text { Proteína do } \\
\text { concentrado } \\
\text { protéico } \\
\text { (mg/g prot.) }\end{array}$ & $\begin{array}{l}\text { Proteína da } \\
\text { FAO }^{1} \\
(\mathrm{mg} / \mathrm{g} \text { prot. })\end{array}$ & $\begin{array}{l}\text { Cômputo } \\
\text { químico }^{2}\end{array}$ & $\begin{array}{c}\text { Proteína } \\
\text { de ovo }^{1} \\
\text { (mg/g prot.) }\end{array}$ & $\begin{array}{l}\text { Cômputo } \\
\text { químico }\end{array}$ \\
\hline Isoleucina & 55,40 & 40,00 & 1,3850 & 54,00 & 1,0259 \\
\hline Leucina & 89,70 & 70,00 & 1,2814 & 86,00 & 1,0430 \\
\hline Lisina & 70,40 & 55,00 & 1,2800 & 70,00 & 1,0057 \\
\hline Metionina & 18,40 & - & - & - & - \\
\hline Cistina & - & - & - & - & - \\
\hline $\begin{array}{l}\text { Sulfurados } \\
\text { totais }\end{array}$ & 18,40 & 35,00 & 0,5257 & 57,00 & 0,3228 \\
\hline Fenil alanina & 131,90 & - & - & - & - \\
\hline Tirosina & 17,50 & - & - & - & - \\
\hline $\begin{array}{l}\text { Aromáticos } \\
\text { totais }\end{array}$ & 149,40 & 60,00 & 2,4900 & 93,00 & 1,6064 \\
\hline Treonina & 41,10 & 40,00 & 1,0275 & 47,00 & 0,8745 \\
\hline Triptofano & - & 10,00 & - & 17,00 & - \\
\hline Valina & 60,70 & 50,00 & 1,2140 & 66,00 & 0,9197 \\
\hline
\end{tabular}

Segundo McDONALD (1981) considera-se a qualidade da proteína no conceito de cômputo químico pela constituição dos aminoácidos essenciais em relação a proteína padrão.

LAJOLO et al. (1982) descreveram as vantagens e desvantagens do método do cômputo químico. As vantagens envolvem simplicidade e baixo custo, facilidade de identificação de fatores limitantes e previsão do valor nutricional ou efeito complementar de misturas. As desvantagens incluem erros na análise de aminoácidos e o fato de não ser considerado o possível 
excesso de aminoácidos, nem a presença de fatores tóxicos, que somente seria detectada em testes com animais.

EUSÉBIO et al. (1968) e JANSEN (1878) perceberam que a qualidade da proteína dependia do perfil e disponibilidade de aminoácidos presentes na proteína alimentar. LAJOLO et al. (1982) afirmaram que a qualidade nutricional da proteína estava ligada a sua capacidade de atender às necessidades orgânicas de crescimento e manutenção.

\section{CONCLUSÃO}

A farinha de feijão guandu (Cajanus cajan (L.) Millsp) apresentou composição química adequada em relação a outras leguminosas.

O procedimento de extração aquosa de proteínas a partir de grãos de feijão guandu permitiu a obtenção de concentrado protéico com 52,45\% de proteína e concentração da ordem de 103,85\%.

O concentrado protéico de feijão guandu (Cajanus cajan (L.) Millsp) apresentou composição química adequada, sendo que cinzas, açúcares solúveis e metionina foram concentrados 122,17, 21,86 e 42,64\%, respectivamente, em relação ao grão.

O cômputo químico indicou que os aminoácidos limitantes primários na farinha e concentrado protéico foram os sulfurados totais.

\section{Abstract}

The aim of this work was the investigation of the chemical properties of Pigeon pea (Cajanus cajan) (L.) Millsp) flour and protein concentrate. The flour presented suitable chemical composition in comparison to other legumes. The water extraction procedure of protein, from Pigeon pea grains with $25,73 \%$ of protein allowed to obtain a protein concentrate with $52,47 \%$ of protein in dry basis, resulting an increase in order of $103,85 \%$. The protein concentrate of Pigeon pea showed suitable chemical composition, having an increase of $122,17 \%$ in ashes and $21,86 \%$ in soluble sugars in relation to the crude grain. The amino acids levels in the concentrate were similar to those in the flour, however there were an increase of $42,64 \%$ in methionine concentration. The chemical score suggest that the primary limiting amino acids in the flour and in the concentrate were the total sulphur amino acids. The chemical composition of the flour and concentrate of Pigeon pea showed perspectives of its utilization as feed components for humans and animals

\section{REFERÊNCIAS}

1 AOAC. Official methods of analysis of AOAC International. Arlington, Virgínia, 1990. v. 1. 
2 BODWELL, C.E. The nutricional importance of protein. Cereal Foods Words, St. Paul, v. 25, n. 7, p. 370-376, 1980.

3 CHANG, K.C.; SATTERLEE, L.D. Chemical, nutritional and microbiological quality of a protein concentrate from culled dry beans. J. Food Sci., Chicago, v. 44, n. 6, p. 1589-1593, 1979.

4 EMBRAPA. Centro Nacional de Pesquisa de Suínos e Aves. Tabela de composição química e valores energéticos de alimentos para suínos e aves. 3.ed. Concórdia, SC., 1991. 97 p. (Documento, 19.).

5 ELIAS, L.G.; HERNANDEZ, M.; BRESSANI, R. The nutritive value of precooked legume flours processed by different methods. Nutrition Reports International, v. 14, n. 4, p. 385-403, 1976.

6 EUSÉBIO, S.; MAMARIL, J.C.; EUSÉBIO, J.A. et al. Studies on Philippine leguminous seeds as protein foods. I. Evaluation of protein quality in some local beans based on their aminoacid patterns. The Philippine Agriculturist, v. 52, p. 211-217, 1968.

7 EUSÉBIO, J.S.; NARCISO, O.D.; QUERUBIN, L.J. Supplementary value of some locally produced legumes to rice/corn and rice-fish corn-fish diets. Technol. J., v. 3, n. 2, p. 64-73, July-Sept., 1977.

8 FAO. Food and Agriculture Organization of the United Nations. Aminoacid content of foods and biological data on proteins. Rome, 1970. $285 \mathrm{p}$.

9 FIALHO, E.T.; ALBINO, L.F. Tabela de composição química e valores energéticos de alimentos para suínos e aves. Concórdia: EMBRAPA/CNPSA, 1983. $23 \mathrm{p}$.

10 GÓMEZ BRENES, R.A.; LISKA, P.; BRESSANI, R. Evaluacion química y biologica de algunas leguminosas de grano. [S.I.]: Instituto de Nutricion de Centro America y Panama, 1976. p. 47-48 (Informe Anual).

11 HOPKINS, D.T.; STEINKE, F.H. Updating protein quality measurement techniques. Cereal Foods Words, St. Paul, v. 23, n. 9 , p. 539-543, 1978.

12 JANSEN, G.R. Biological evaluation of protein quality. Food Technol., Chicago, v.32, n.12, p.52-56, 1978.

13 KRISHNA, T.G.; BHATIA, C.R. Vicilin from cajanus cajan seeds. Phytochemistry, Oxford, v. 24, n. 10, p. 2201-2203, 1985. 
14 BRASIL. Ministério da Agricultura. Secretaria Nacional de Defesa Agropecuária. Laboratório Nacional de Referência Animal. Métodos analíticos para controle de produtos de origem animal e seus ingredientes. II Métodos microbiológicos e métodos físicos e químicos. Brasília, 1981. p.II-11 a II-13.

15 LAJOLO, F. M.; SANTOS, A. C.; WILSON, E. D. Proteínas e aminoácidos. In: OLIVEIRA, J.E.D.; SANTOS, A.C.; WILSON, E.D. Nutrição básica. São Paulo: Sarvier Editora de Livros Médicos, 1982. Cap. 4. p. 29-65.

16 FAE. Manual de métodos analíticos oficiais FAE de controle de qualidade. Brasília: Ministério da Educação, 1988. p. 77-78(3). (Manual técnico, Versão 03).

17 MAURON, J. The analysis of food proteins, aminoacid composition and nutritive value. In: PORTER, J.W.G.; ROLLS, B.A. Proteins in human nutrition. London: Academic Press, 1973. Chapter 9, p.139154.

18 McDONALD, P.; EDWARDS, R.A.; GREENHALGH, J.F.D. Animal nutrition. $3^{\text {th }}$.ed. New York: Longman, 1981. 479 p.

19 MOORE, S.; STEIN, W. Chromatografic determination of amioacids by the use of automatic recording equipament. Meth. Enzymol., v. 6, p. 819-831, 1963.

20 PEARSON, A.M. Soy proteins. In: HUDSON, B.J.F. Developments in food proteins-2. London: Academic Press, Applied Science Publishers, 1983. Chapter 2, p. 67-108.

21 SALUNKHE, D.K.; KADAM, S.S.; CHAVAN, J.K. Postharvest biotechnology of food legumes. Flórida: CRC Press, 1985. 160 p.

22 SALUNKHE, D.K.; CHAVAN, J.K.; KADAM, S.S. Pigeonpea as an important food source. CRC critical Reviews in Food Science and Nutrition, Boca Raton, v. 23, n. 2, p. 103-145, 1986.

23 SANKARA RAO, D.S.; DEOSTHALE, Y.G. Mineral composition of four Indian food legumes. J. Food Sci., Chicago, v. 46, n. 6, p. 19621963, 1981.

24 SATHE, S.K.; DESHPANDE, S.S.; SALUNKHE, D.K. Dry beans of phaseolus. A Review. Part 1. Chemical Composition: protein. CRC Critical Review in Food Science and Nutrition, Boca Raton, v. 20, n. 1, p. 1-46, 1984. 
25 SINGH, U.; JAMBUNATHAN, R. Methods for the estimation of protein in Pigeonpea (Cajanus cajan (L.) Millsp.) and the relationship between whole grain and dhal protein contents. J. Sci. Food. Agric., Chicago, v. 32, p. 705-710, 1981.

26 SINGH, U.; JAMBUNATHAN, R.; GURTU, S. Seed protein fraction and aminoacid composition of some wild species of Pigeon pea. J. Food Sci. Technol., v. 18, p. 83-85, 1981.

27 SINGH, U.; VORAPUTHAPORN, W.; RAO, P.V.; JAMBUNATHAN, R. Physicochemical characteristics of Pigeonpea and Mung bean starches and their noodle quality. Journal of Food Science, Chicago, v. 54, n. 5, p. 1293-1297, 1989.

28 SINGH, U.; JAIN, K.C.; JAMBUNATHAN, R. et al. Nutritional quality of vegetable Pigeon peas (Cajanus cajan (L.) Mill sp.): Dry matter accumulation, carbohydrates and proteins. J. Food Sci., Chicago, v. 49 , n. 2, p. 799-802, 1984a.

29 SINGH, U.; JAIN, K.C.; JAMBUNATHAN, R. et al. Nutritional quality of vegetable Pigeon peas (Cajanus cajan (L.) Mill sp.): Mineral and trace elements. J. Food Sci., Chicago, v. 49, n. 2, p. 465-646, 1984b.

30 SINGH, H.; RAO, P.V.; SUBRAHMANYAM, N. et al. Cooking characteristics, chemical composition and protein quality of newly developed genotypes of Pigeon pea (Cajanus cajan L.). Journal of the Science of Food Agriculture, v. 61, n. 4, p. 395-400, 1993.

31 SOUZA, P.A.; SOUZA, H.B.A.; SANTOS, J.E. et al. Avaliação físicoquímica e nutricional de grãos de feijão-guandu (Cajanus cajan (L.) Mill sp). Alim. Nutr., São Paulo, v. 3, p. 51-62, 1991.

32 SPACKMAN, D. H.; STEIN, W. H.; MOORE, S. Automatic recording aparatus for use the chromatography of aminoacids. Analitycal Chemistry, Washington, v. 30, n. 7, p. 1190-1206, 1958.

33 SULLIVAN, D.M.; CARPENTER, D.E. Methods of analysis for nutrition labeling. Arlington, Virgínia, USA: AOAC International, 1993. Chapter 29.

34 VILELA, E.R.; EL-DASH, A.A. Produção de farinha de guandu (Cajanus cajan, Millsp): moagem por via seca. Boletim da Sociedade Brasileira de Ciência e Tecnologia de Alimentos, Campinas, v. 19, n. 2, p. 101-108, 1985.

35 WALKER, A.F. The estimation of protein quality. In: HUDSON, B.I.F. (Ed.). Developments in food protein-2. London: Academic Press, Applied Science Publishers, 1983. v. 2, Chapter 8. 